Rhinehammer, T. B. \& LAMBerger, P. H. (1973). Tritium Control Technology. WASH-1269, Division of Operational Safety, U.S. Atomic Energy Commission, Washington, D.C.: $\mathrm{x}+530 \mathrm{pp}$.

Rose, D. J. (1969). Engineering feasibility of controlled fusion. Nuclear Fusion, 9, pp. 183-203.

U.S. Atomic Energy Commission (1973). Fusion Power: An Assessment of Ultimate Potential. WASH-1239,
Division of Controlled Thermonuclear Research, USAEC, Superintendent of Documents, U.S. Government Printing Office, Washington, D.C.: iii + 62 pp., illustr.

Wolkenhauer, W. C., Leonard, B. R., Jr \& Gore, B. F. (1973). Transmutation of High-level Radioactive Waste with a Controlled Thermonuclear Reactor. BNWL-1772, Battelle Pacific Northwest Laboratories, Richland, Washington: vii +168 pp., illustr.

\title{
Nuclear Power-stations in Switzerland
}

Switzerland, whose terrain contains no exploitable fossil fuel and has neither large and dry sunny expanses suitable for collecting solar energy nor volcanic regions allowing the use of geothermal energy, whose climate does not include enough regular strong winds for exploitation of aeolian energy on a large scale, whose geographical position rules out the possibility of recourse to tidal or submarine energy, whose development of hydroelectric facilities has been almost completed, and whose government bans the building of new thermal power stations because of the resultant air pollution, now only has the choice between atomic fission and large-scale efforts to restrict the use of electric current. Moreoever, if Switzerland does not want to find herself out of pocket from buying at ever-increasing prices the oil needed to heat apartments-incidentally very polluting-she must replace these heating systems by a central urban heating unit, fed by an electric power-station or by the heat lost during the cooling-down of the steam emanating from the turbines of a nuclear power-station.

At present the total energy consumed per annum in Switzerland amounts to about 155,000 Tcal (one million $\mathrm{kWh}=0.86 \mathrm{Tcal}$ ), $80 \%$ of which comes from oil (oil fuel, petrol, etc.), $15 \%$ from hydroelectric power-stations, and the ramaining $5 \%$ from coal, wood, natural gas, and atomic fission. If we consider merely the electric current consumed per annum in Switzerland, i.e. about 32 thousand million $\mathrm{kWh}$, increasing each year by 5 to $6 \%$, about $80 \%$ comes from hydroelectric power-stations, $15 \%$ from three nuclear power-stations (Mühleberg, Beznau I, and Beznau II) already functioning, and $5 \%$ from two thermal oil powet-stations located at Chavalon (Valais) and Cornaux (Neuchâtel).
Despite the difficulties arising from the very democratic Swiss Constitution, which gives considerable rights to the cantons, communes, and ordinary citizens by way of referendums, and despite public opinion which is often badly informed as to the possible dangers of nuclear powerstations, the Federal Government has authorized three new ones-at Leibstadt (950 MW), Gösgen (910 MW), and Kaiseraugst (920 MW), which are now under construction. As all three are situated on the Rhine or on one of its affluents, they will have to be equipped with cooling towers in order not to overheat the waters of the river. In addition there are three projected stations at Graben (Bern), Inwil (Lucerne), and Rüthi (St. Gall), which will also have to be equipped with cooling towers. With regard to the Verbois project on the Rhône downstream from Geneva, the only one planned for French-speaking Switzerland, the intention here is to use for cooling purposes the waters of the Rhône, which can be made sufficiently abundant at all times of year by adjusting the level of Lake Geneva.

For all these power-stations the choice has been made of slow-neutron reactors, using uranium originating in the United States of America and enriched to about 3\%, with cooling of the reactor by ordinary water and preferably using the PWR (Pressurized Water Reactor) version. The Swiss government refuses to accept the more profitable but less safe fast-neutron breeder reactors, as public opinion would not agree to the sacrificing of security for the sake of economic yield.

Georges KarL

15 chemin de Roches 1208 Geneva Switzerland.

\section{Literature on Air Pollution and Lichens}

The literature dealing with the effects of air pollutants on lichens is very scattered and, prior to the publication of Air Pollution and Lichens (Ferry, B.W., Baddeley, M.S., \& Hawksworth, D.L., Eds, Athlone Press of the University of London, London, and University of Toronto Press, Toronto, $1973^{*}$ ), no attempt had been made to collate it. As this field is not adequately covered at the present time by any existing abstracting service, a series of papers, including titles and brief abstracts of pertinent articles, has started to appear annually in The Lichenologist (the Journal of the British Lichen Society, published twice-yearly by Academic Press Inc. (London) Ltd, 24-28 Oval Road, London, NW1, England, which is issued free to members of the Society; subscription for non-member $£ 6.00$ (inland) or $£ 6.90$ (abroad) p.a. incl. postage). The series is being compiled by the undersigned and entitled 'Literature on Air Pollution and Lichens'. The first number in it appeared in Vol. 6(1) pp. 122-5 (1974) and listed 40 titles, while the second, scheduled to appear in 7(1) (1975), will include at least a further 35 papers. Most papers included in each number of the series will have appeared within the preceding 12 months.

It is hoped that this series, in addition to providing a continuing bibliography of the subject, will serve to make workers in various parts of the world aware as rapidly as possible of studies that are being reported elsewhere. For consideration for this series, the undersigned would be pleased to receive copies of papers in this field from their authors as soon as possible after publication.

\section{DAVID L. HAWKSWORTH \\ Commonwealth Mycological Institute Ferry Lane, Kew \\ Surrey, England.}

* See the review by J. R. Laundon, of the British Museum (Natural History), in our next issue.-Ed. 